\title{
Focused Ion Beam on Radioactive Specimens: Operational Challenges and Approach
}

\author{
Arash Parsi ${ }^{1}$ and Paula D. Freyer ${ }^{1}$ \\ ${ }^{1 .}$ Westinghouse Electric Co LLC, Global Technology Development, Pittsburgh, PA, USA
}

Nuclear power is unique among the power generation methods because it utilizes nuclear fission as the heat source, plants operate uninterrupted at near full capacity for 18-24 months without refueling, and the core continues to generate heat even after shut down. It is also unique because the neutron fields generated during operation affect the mechanical properties of components exposed to the neutrons, especially components located closest to the fuel. As the worldwide nuclear fleet evaluates the licensing requirements to extend plant operating life beyond 60 years, characterization of the effects of neutron irradiation on plant components and understanding the link between operating environment, material microstructure and mechanical properties will be central area of study.

Neutron irradiation alters materials in a number of ways. The primary affect is that neutron collision with the atoms in the metal matrix displaces atoms within the crystal lattice, the cumulative effect of which is the formation of dislocations and voids [1]. These defects harden and embrittle components, over time can alter allowable reactor heating and cooling rates, and typically increase the susceptibility of austenitic alloys to failure mechanisms such as stress corrosion cracking (SCC). Neutron absorption also activates the target material, the prime example being the thermal neutron activation of natural cobalt $\left({ }^{59} \mathrm{Co}\right)$ in various alloys to ${ }^{60} \mathrm{Co}$, which is the largest and most persistent contributor to personnel radiation exposure. A typical highly irradiated stainless steel component can have near-contact radiation dose exceeding thousands of roentgens per hour $(\mathrm{R} / \mathrm{hr})$. Given that the lethal dose to cause $50 \%$ mortality in 30 days $\left(\mathrm{LD}_{50 / 30}\right)$ are $\sim 400-450$ rem (roentgen equivalent in man) [2], an unprotected individual in close proximity to such a specimen could receive the lethal dose in less than 1 hour. The latter effect makes a simple characterization task into a very expensive one requiring the use of specialized hot cell facilities, instrumentation, and handling protocols.

The Westinghouse Hot Cell Facility (W-HCF) is located in Pittsburgh, PA and is one of few commercial facilities of its type in the U.S. The purpose of this facility is to perform research and to evaluate, test and characterize highly radioactive materials for internal and external customers (plants, universities and national labs) worldwide. Westinghouse has been studying neutron-induced voids in a number of materials exposed to very high neutron fluences [3]. Figure 1 shows images of radiation induced voids in Type 304 stainless steel and Alloy X-750 obtained by TEM.

FIB is the method of choice to provide site-specific samples for TEM analysis, but operating an instrument for characterization of radioactive specimens poses challenges, which broadly are: (1) sample handling and transportation, (2) exposure to the operator, and (3) service and maintenance.

The Westinghouse requirements for specimen transport is the same for any instrument and is dictated by the maximum measurable radiation level on the outside of the transport container. For internal work, the level outside the container or the instrument should be $<2 \mathrm{mR} / \mathrm{hr}$ on contact. Achieving these levels require shielding the specimen in lead transfer vessels nested inside drums to increase distance and reduce dose. Therefore, our strategy has been to reduce the sample to the bare minimum manageable 
size to reduce the radiation fields. As such, it is crucial to maintain hot cell equipment for TEM foil preparation (precision saws, jet electropolishers) simply to prepare a sample suitable for FIB analysis.

The second obstacle is operator access. For an operator not trained as a radiological worker, the exposure limit is $2 \mathrm{mR} / \mathrm{day}$. To achieve this low exposure, the FIB can be operated remotely using a cloned computer and extending the range of the control equipment such as nanomanipulator. However, by providing radiation training to the operator, the exposure limits is increased to up to $5 \mathrm{mR} / \mathrm{hr}$, which removes the hurdle of remote operation in all but the most radioactive specimens.

The third obstacle is the chronic contamination of the internal parts of the FIB and its implications on instrument serviceability. Since FIB necessitates milling away a microscopic portion of the sample, the removed material deposits on internal surfaces. Rather than use internal labor, Westinghouse trains vendor service engineers to become radiological workers so they can service the instrument. However, the working assumption is that most parts that are inside the chamber cannot be repaired under warranty or service contract coverage, because they cannot be removed and "free-released" for off-site repair. In addition to contaminated SEM and FIB objective pole pieces, the stage, backscatter detector, in situ nanomanipulator and even the In-Lens detector can become de facto consumables.

\section{References:}

[1] Itoh, Onose, and Yuhara, "Void Swelling and Microstructural Change in Neutron Irradiated Type 316 Stainless Steel," Radiation-Induced Changes in Microstructure: $13^{\text {th }}$ International Symposium (Part I), ASTM STP 955, F.A. Garner, N.H. Packan, and A.S. Kumar, Eds., (ASTM, Philadelphia), 1987, pp. 114-126.

[2] United States Nuclear Regulatory Commission Website, http://www.nrc.gov/reading-rm/basicref/glossary/lethal-dose-ld.html.

[3] Wiezorek et al, Microscopy \& Microanalysis, 30 (2014) p. 1822.

[4] The authors wish to thank Dr. Lucille Giannuzzi for invaluable help in preparing and imaging radioactive FIB specimens

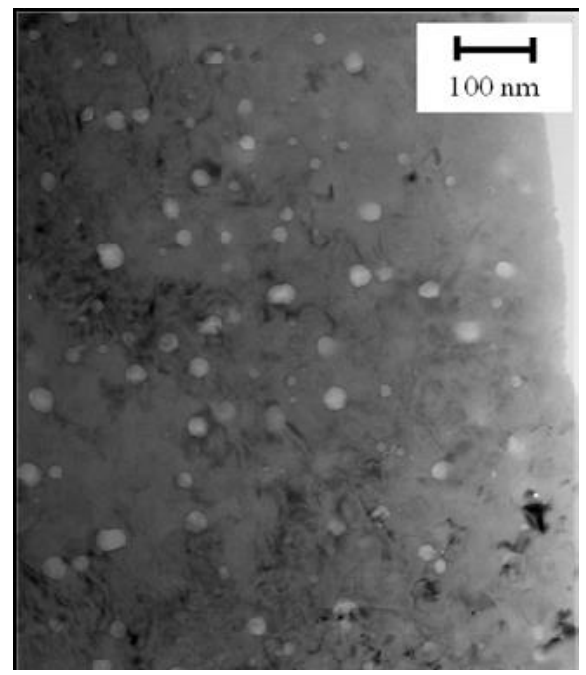

(a)

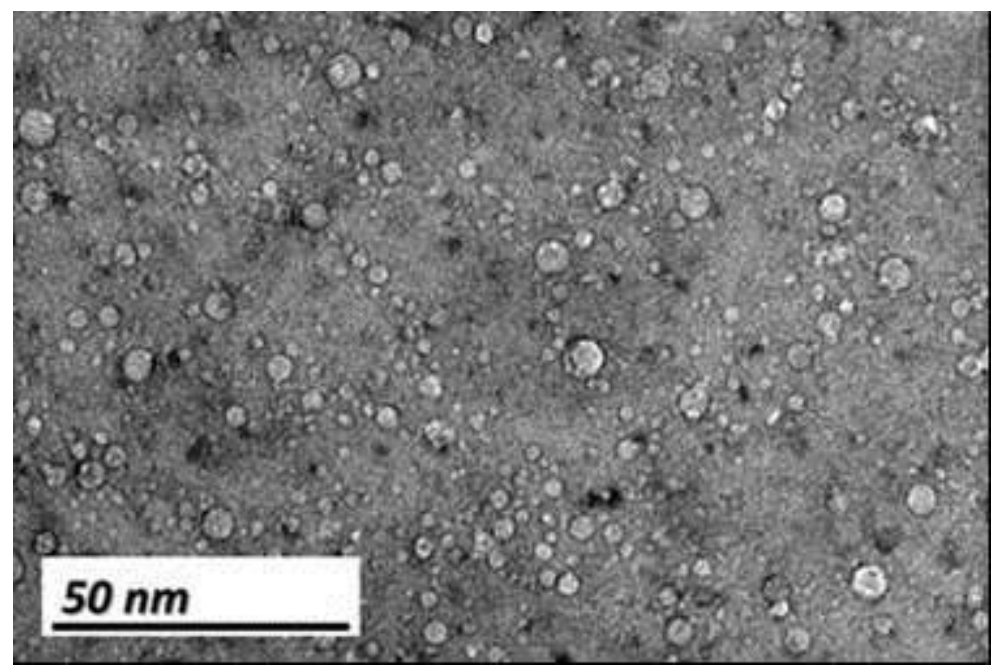

(b)

Figure 1. Neutron Irradiation Induced Voids in Highly Irradiated (a) Type 304 Stainless Steel prepared by thin foil method and [3] (b) Inconel X-750 FIB lamella [4] 